\title{
Effects of spinal stabilization exercise with real-time ultrasound imaging biofeedback in individuals with chronic nonspecific low back pain: a pilot study
}

\author{
Raheem Sarafadeen ${ }^{1,2}$, Sokunbi O. Ganiyu', Aminu A. Ibrahim ${ }^{1,3, *}$ \\ 'Department of Physiotherapy, Faculty of Allied Health Sciences, College of Health Sciences, Bayero University Kano, Kano State, Nigeria \\ ${ }^{2}$ Department of Physiotherapy, National Orthopedic Hospital, Dala, Kano State, Nigeria \\ ${ }^{3}$ Department of Physiotherapy, Muhammad Abdullahi Wase Teaching Hospital, Hospital Management Board, Kano State, Nigeria
}

The use of real-time ultrasound imaging (RUSI) as biofeedback to enhance the performance of spinal stabilization exercise and recovery from low back pain has been a recent trend in musculoskeletal rehabilitation. The aim of this pilot study was to evaluate whether it would be feasible to conduct a randomized controlled trial investigating the effects of spinal stabilization exercise with RUSI biofeedback in individuals with chronic nonspecific low back pain. This was a single-group pretest-posttest quasi-experimental study. Ten consecutive patients with chronic nonspecific low back pain met the study criteria. They received spinal stabilization exercise with the RUSI biofeedback focusing on lumbar multifidus muscle activation. The intervention was provided twice weekly for 6 weeks. Outcome measures were lumbar multifidus muscle cross-sectional area, pain, disability and quality of life assessed at baseline and after intervention. A paired $t$-test was applied and effect size (Cohen $d$ ) was computed. The recruitment and retention rates were
$75 \%$ and $83 \%$ respectively. No adverse events were reported during the study. Compared with the baseline, the participants demonstrated statistically significant improvement in lumbar multifidus muscle crosssectional area $(P<0.05, d=1.03)$, pain $(P<0.001, d=2.56)$ and disability $(P<0.05, d=1.43)$ with large effect size after the intervention. However, no statistically significant differences were observed for physical and mental health $(P>0.05)$ after the intervention. It was concluded that spinal stabilization exercise with RUSI biofeedback is effective in improving lumbar multifidus muscle cross-sectional area, pain and disability in individuals with chronic nonspecific low back pain. The results demonstrated the feasibility of conducting a future, larger-scale powered randomized controlled trial to confirm these preliminary findings.

Keywords: Chronic nonspecific low back pain, Spinal stabilization exercise, Lumbar multifidus muscle, Cross-sectional area, Pain, Disability

\section{INTRODUCTION}

Low back pain (LBP) has been considered to be one of the most painful health problems worldwide and recorded to be the most commonly managed condition in healthcare settings (Hartvigsen et al., 2018; Kovacs et al., 2012). It is defined as pain, muscle tension, or stiffness localized below the 12th costal margin and above the inferior gluteal folds, with or without leg pain (Chou, 2010). LBP is a major public health issue as it adversely affects the patient's well-being and quality of life, and contributes largely to the burden of disease globally (Dagenais et al., 2008).
The burden of LBP is enormous in terms of economic, health and societal costs. The direct and indirect cost of LBP in the US has been reported between $\$ 84.1$ billion and $\$ 624.8$ billion, with lost work productivity resulting in indirect costs of $\$ 7.4$ billion to $\$ 28$ billion (Dagenais et al., 2008). The incremental expenditures due to LBP were estimated around \$26 billion (Luo et al., 2004). Moreover, the burden of LBP is projected to upsurge in the coming decades especially in low-income and middle-income countries mainly due to population growth and aging (Hartvigsen et al., 2018).

According to previous reviews, the prevalence of LBP in Africa
${ }^{*}$ Corresponding author: Aminu A. Ibrahim (D) https://orcid.org/0000-0002-5711-1639 Department of Physiotherapy, Faculty of Allied Health Sciences, College of Health Sciences, Bayero University Kano, P.M. B 3011, Kano State, Nigeria

E-mail: amenconafs@gmail.com

Received: May 5, 2020 / Accepted: May 25, 2020
This is an Open Access article distributed under the terms of the Creative Commons Attribution Non-Commercial License (https://creativecommons.org/licenses/by-nc/4.0/) which permits unrestricted non-commercial use, distribution, and reproduction in any medium, provided the original work is properly cited. 
is rising and comparable to that of western nations (Louw et al., 2007; Morris et al., 2018). In a review conducted by Morris et al. (2018), the annual LBP prevalence among Africans was found to be $57 \%$ which is considerably higher than the $38.5 \%$ estimated globally (Hoy et al., 2012). In another review, it was found that workers (48\%) are the most common population group presenting with LBP while scholars comprised $15 \%$ of the population (Louw et al., 2007). In Nigeria, the annual prevalence of LBP has been reported ranging between $40 \%$ and $74 \%$, which affects mostly the rural income communities (Omokhodion, 2002; Tella et al., 2013).

Although LBP is often considered as a complex or multifactorial disorder with many potential causative factors, in majority of cases (90\%), the cause of the pain is unknown which is commonly referred to as nonspecific LBP (Balagué et al., 2012). However, there are different interpretations of the underlying mechanisms of pain even when specified radiological diagnoses are established (Hildebrandt et al., 2017). One mechanism that has been linked with LBP is the altered stability and motor control of specific muscles of the trunk. Morphological studies show that lower cross-sectional area (CSA) (Danneels et al., 2000; Hides et al., 2008; Kamaz et al., 2007) and a greater percentage of intramuscular fat (Alaranta et al., 1993; Mengiardi et al., 2006) in the lumbar multifidus muscle is evident in individuals with chronic LBP. Moreover, there is evidence to suggest that training leading to activation and strengthening of the lumbar multifidus muscle may alleviate symptoms of LBP (Goldby et al., 2006; Hides et al., 2008; Ibrahim et al., 2018). Thus, rehabilitating this musculature is considered essential for individuals with chronic low back disorders.

The use of real-time ultrasound imaging (RUSI) as biofeedback to enhance the performance of spinal stabilization exercise and recovery from LBP has been a recent trend in musculoskeletal rehabilitation. RUSI has been used successfully to evaluate the thickness of deep trunk muscles (Akbari et al., 2008; Ehsani et al., 2019; Shamsi et al., 2016) and to provide visual feedback of these muscles' activation in both healthy and symptomatic individuals (Henry and Teyhen, 2007; Henry and Westervelt, 2005; Lee et al., 2018; Van et al., 2006). While specifically the use of RUSI has been shown to improve preferential activation of the lumbar multifidus muscle in individuals with LBP (Hides et al., 1996; Hides et al., 2012), however, the effects of this treatment approach in individuals with chronic nonspecific LBP (CNLBP) appeared not to have been widely reported. However, prior to conducting a larger-scale randomized controlled trial (RCT) to test the efficacy of this treatment approach, it is important to carry out a pilot study to evaluate the feasibility for such a larger trial so that resources and efforts are not wasted (Thabane et al., 2010).

Therefore, the aim of this pilot study was to evaluate whether it would be feasible to conduct a RCT investigating the effects of spinal stabilization exercise with RUSI biofeedback in individuals with CNLBP.

\section{MATERIALS AND METHODS}

\section{Study design}

This pilot study adopted a single-group pretest-posttest quasi-experimental design and was conducted between July and October 2018 at the out-patient unit of physiotherapy department, National Orthopedic Hospital, Dala, Kano State, Northwestern Nigeria.

\section{Ethical consideration}

Ethical clearance was sought and obtained from the Research and Ethical Committee of National Orthopedic Hospital, Dala, Kano State (Ref: NOHD/RET/ETHIC/60) before the commencement of the study.

\section{Participants and flow}

The participants were consecutive patients with chronic LBP referred for physiotherapy by consultant orthopedic surgeons from the general out-patient department of National Orthopedic Hospital, Dala, Kano State. The participants were eligible for the study if they were both male and female between the age of 18 and 60 years, had primary complaint of nonspecific LBP of at least 3-month duration with and without pain radiating to one or both lower limbs, and able to read and understand English language and or Hausa language. Participants were excluded if they had a history of spine surgery, pregnancy and serious spinal pathology such as fracture, infection and metastases. Other exclusion criteria included a history of neurosis, depressive symptomatology and other LBP yellow flag factors as all these factors could potentially skew the data.

The eligibility of the participants was ensured by the primary investigator (RS) through history taking and physical examination. All participants were made to sign an informed consent after detailed information of the study was provided. It was also made known to them that their participation in the study was free and can discontinue from the study if so wish. Participants were also informed about the importance of adherence to protocol and prescribed home program when the intervention started. 


\section{Baseline assessments}

Demographic data consisting of age, gender, body mass index (BMI), duration of back pain, and occupational status were collected using a researcher designed form. Clinical outcome assessments involved measurement of lumbar multifidus muscle CSA with a D3 ultrasonic diagnostic imaging system (primary outcome) and evaluation of pain, functional disability and quality of life using self-report measures.

\section{Sample size estimation}

A formal sample size calculation was not conducted for this study since it was a pilot study. However, we thought that recruiting 10-12 participants would be adequate to give an insight into the study feasibility.

\section{Outcome assessments}

\section{Recruitment rate}

This was expressed as the percentage of eligible participants that consented to participation (Ibrahim et al., 2018).

\section{Retention rate}

This was expressed as the percentage of participants who completed the intervention without loss to follow-up. An acceptable retention rate was set at least half (50\%) of the participants completing the interventions (Ibrahim et al., 2018).

\section{Adverse events}

All participants were informed prior to intervention to contact the research coordinator via phone or during follow-up visits in case they experience any unexpected serious adverse event such as exacerbating back pain, excessive fatigue, light-headedness. And shortness of breath or dizziness during the study.

\section{Lumbar multifidus muscle CSA}

The imaging of the lumbar multifidus muscle CSA was assessed using a D3 ultrasonic diagnostic imaging system with $5-\mathrm{MHz}$ coplanar transducer. The procedure for the measurement is identical to that described by Sokunbi et al. (2008). Participants were asked to assume prone lying position with proper pillow support and the neck turned to the participants' preferred side. The lumbar spine was palpated cranially from the line joining the superior border of the iliac crest (L4/L5) to locate the position of L5 spinous process. It is a deep small blunted bony point lying at the center of the lumbosacral depression. L5/S1 position was checked and confirmed against the lumbosacral depression as seen on the ultrasound image. The ultrasound imaging transducer head with a coupling medium was then placed at the L5/S1 level and moved laterally and angled in a cephalocaudal direction to obtain a clear visualization of the zygapophyseal joints, muscle bulk, thoracolumbar fascia, and echogenic lamina of L5 spinous process. The clearest image of lumbar multifidus muscle was captured and the CSA was determined as stipulated in the manual of the D3 ultrasonic diagnostic imaging system version.

\section{Pain intensity}

The levels of the pain intensity of the participants were assessed by administering the Hausa Numerical Pain Rating Scale (NPRS; 0-10 cm) (Ibrahim et al., 2020a), with 0 representing "no pain" and 10 representing "worst imaginable pain." The participants were asked to mark the number that best reflects their current pain at rest. The Hausa NPRS has been shown to be a reliable, valid and responsive measure of pain intensity among patients with chronic LBP (Ibrahim et al., 2020a).

\section{Functional disability}

This was assessed by administering the Roland Morris Disability Questionnaire (RMDQ). It is a 24-item questionnaire, and the scores range from 0 (no disability) to 24 (maximum disability). The participants were asked to choose from the 24 items as it suitable for their current disability level. The RMDQ score is calculated by adding up the number of items checked. The RMDQ has good psychometric properties in terms of reliability and validity (Chiarotto et al., 2016; Roland and Fairbank, 2000). Prior to data collection, the questionnaire was translated into Hausa using the recommended guidelines for translation and cross-cultural adaptation of self-reported measures (Beaton et al., 2000).

\section{Quality of life}

The quality of life of the participants was assessed by administering the Hausa short-form health survey (SF-12) questionnaire (Ibrahim et al., 2020b). It is a shorter version of the SF-36 which comprises physical component scores (PCS-12) and mental component scores (MCS-12). To compute the PCS-12 and MCS-12, a web-based scoring tool (www.orthotoolkit.com/sf-12/) was used. Higher scores reflect better health status. The Hausa SF-12 was found to have adequate psychometric properties in terms of reliability, construct validity and factorial invariance among patients with chronic LBP (Ibrahim et al., 2020b). All clinical outcomes (lumbar multifidus muscle CSA, pain intensity, functional disability and quality of life) were assessed at baseline and after treatment. 


\section{Interventions}

All the interventions in this study (i.e., stabilization exercise with RUSI biofeedback) were provided by the primary researcher and a research assistant (AI) who was a consultant radiologist with over 10 years of experience in diagnostic ultrasound imaging. Participants were instructed on how to activate and contract the lumbar multifidus muscle in synergy with other muscles of core stabilization using bracing methods. Participants were asked to assume prone lying with proper pillow support and the neck turned to the participants' preferred side as described under the lumbar multifidus muscle CSA measurement. While in this position, the ultrasound transducer head was placed at the L5/S1 level and the participants were then instructed to contract the core stability muscles as previously thought. They were also instructed to focus on the monitor to see the changes in the thickness of lumbar multifidus muscle CSA as they undergo the contraction and put in their best effort to increase the thickness with successive contractions. Ten sets of contractions, holding each contraction for $10 \mathrm{sec}$ were carried out with a period of 2-min rest in between contractions. The entire exercise period lasted for $30 \mathrm{~min}$. Treatment was carried out twice a week for 6 weeks.

\section{Data analysis}

All statistical analyses were conducted using IBM SPSS Statistics ver. 20.0 (IBM Co., Armonk, NY, USA) with 0.05 set as level of significance. Normality test for the dependent variables was verified using the Shapiro-Wilk test. Descriptive statistics of mean, standard deviation, frequencies and percentages were used to summarize the data. Inferential statistics using paired $t$-test (normally distributed data) was applied to analyze the differences between pre- and postintervention in lumbar multifidus muscle CSA, pain intensity, functional disability and quality of life mean scores. Effect size was calculated using the formula $d=t / \sqrt{ } \mathrm{N}$, where $t$ is $t$-score and $\mathrm{N}$ is the total sample size. Effect size values were considered according to Cohen $\mathrm{d}$ as either trivial $(<0.2)$, small $(\geq 0.2$ and $<0.5)$, moderate $(\geq 0.5$ and $<0.8)$, or large $(\geq 0.8)$.

\section{RESULTS}

Sixteen participants were assessed for the study eligibility of which 12 fulfilled the inclusion criteria, yielding a recruitment rate of $75 \%$ (12 of 16). Two of the excluded participants were due to the inability to fulfill our age criteria (i.e., $>60$ years) and the other two had a history of back surgery. Of the 12 consented participants, only 10 (five males and five females) completed the intervention representing a retention rate of $83 \%$ (10 of 12). The reasons for the dropout were serious illness and traveling. The participants reported no adverse events during the study. The so-

Table 1. Socio-demographic characteristics of the participants

\begin{tabular}{lc}
\hline Variable & $(\mathrm{N}=10)$ \\
\hline Age $(\mathrm{yr})$ & $49.6 \pm 22.3$ \\
Gender & $5(50.0)$ \\
Male & $5(50.0)$ \\
Female & $1.72 \pm 0.09$ \\
Height $(\mathrm{m})$ & $65.0 \pm 12.4$ \\
Weight $(\mathrm{kg})$ & $21.9 \pm 3.68$ \\
Body mass index $\left(\mathrm{kg} / \mathrm{m}^{2}\right)$ & $2.6 \pm 0.69$ \\
Pain duration $(\mathrm{yr})$ & \\
Marital status & $9(90.0)$ \\
Married & $1(10.0)$ \\
Single & \\
Educational status & $0(0.0)$ \\
None & $3(30.0)$ \\
Completed primary education & $3(30.0)$ \\
Completed secondary education & $4(40.0)$ \\
Completed tertiary education & \\
Occupational status & $4(40.0)$ \\
House wife & $3(30.0)$ \\
Civil servant & $3(30.0)$ \\
Trader & \\
\hline
\end{tabular}

Values are presented as mean \pm standard deviation or number $(\%)$.

Table 2. Pretest and posttest scores of clinical outcomes among the participants $(n=10)$

\begin{tabular}{|c|c|c|c|c|c|}
\hline Variable & Pretest & Posttest & Difference (95\% Cl) & $P$-value & Effect size \\
\hline LMM CSA & $8.15 \pm 2.05$ & $9.87 \pm 2.97$ & $-1.72 \pm 1.65(-2.90$ to -0.53$)$ & $0.010^{*}$ & 1.03 \\
\hline Pain intensity & $6.70 \pm 0.48$ & $2.80 \pm 1.22$ & $3.90 \pm 1.52$ (2.80 to 4.99$)$ & $0.000^{* *}$ & 2.56 \\
\hline Functional disability & $8.60 \pm 3.77$ & $4.10 \pm 1.52$ & $4.50 \pm 3.13(2.25$ to 6.74$)$ & $0.001^{*}$ & 1.43 \\
\hline Physical health (PCS-12) & $32.4 \pm 5.99$ & $41.3 \pm 18.6$ & $-8.86 \pm 17.8(-21.6$ to 3.90$)$ & 0.151 & 0.49 \\
\hline Mental health (MCS-12) & $39.4 \pm 6.16$ & $43.4 \pm 22.2$ & $-4.02 \pm 21.7(-19.5$ to 11.5$)$ & 0.572 & 0.18 \\
\hline
\end{tabular}

Values are presented as mean \pm standard deviation.

$\mathrm{Cl}$, confidence interval; LMM, lumbar multifidus muscle; CSA, cross-sectional area; PCS-12, physical component scores; MCS-12, mental component scores.

* Significant at $P<0.05$. ${ }^{*}$ Significant at $P<0.001$. 
cio-demographic characteristics of the participants are presented in Table 1. The participants' mean age and BMI were $49.6 \pm 22.3$ years and $21.9 \pm 3.68 \mathrm{~kg} / \mathrm{m}^{2}$ respectively.

Table 2 shows changes in clinical outcomes after the intervention among the participants. Results of the paired $t$-test revealed statistically significant differences in lumbar multifidus muscle $\operatorname{CSA}(P=0.010, d=1.03)$, pain intensity $(P=0.000, d=2.56)$, and functional disability $(P=0.001, d=1.43)$ with large effect size after the intervention. However, no statistically significant differences were observed for physical and mental health $(P>0.05)$ after the intervention (Table 2).

\section{DISCUSSION}

This pilot study assessed the feasibility of conducting a future larger-scale, powered RCT to examine the efficacy of spinal stabilization exercise with RUSI biofeedback in individuals with CNLBP. The results of the study suggested the feasibility in terms of recruitment rate, retention rate, safety and potential effects of treatment on lumbar multifidus muscle CSA, pain intensity and functional disability.

The feasibility of conducting a larger-scale, powered RCT was demonstrated by the excellent recruitment and retention rates as well as safety of the intervention. Even though we did not recruit a large number of participants in the current study, the recruitment period was short and only four participants out of the 16 assessed were excluded. One of the reasons for the exclusion was due to overage ( $>65$ years). This criterion, however, would be relaxed while recruiting participants for the large RCT to have more representation. Interestingly, there was an equal distribution of the participants with regard to gender signifying that both males and females were equally affected and gender bias was eliminated.

Regarding lumbar multifidus muscle CSA, it has been well documented that this muscle is atrophying in individuals suffering from LBP with or without leg pain (Danneels et al., 2000; Hides et al., 2008; Kader et al., 2000; Kamaz et al., 2007). This was also anticipated among the participated individuals in the current study as they were all sufferers of chronic LBP. The stabilization exercise with RUSI biofeedback employed proved to be valuable in activating their lumbar multifidus muscle evidenced by the improvement in the CSA with large effect size after completion of the study despite the smaller sessions of treatment. In support of this finding, the use of RUSI as a biofeedback tool has been reported by several authors to enhance preferential activation of the lumbar multifidus muscle in individuals with (Hides et al., 1996;
Hides et al., 2008; Maraschin et al., 2014) or without (Van et al., 2006) LBP. According to the above authors, preferential activation of the lumbar multifidus muscle was significantly associated with its recovery, performance, and retention in the ability to activate the muscle as well as a limited number of treatment sessions. The focus of stabilization exercise is to improve the activation pattern of deep trunk muscles and restore functional posture and movement control, which in turn may help to relieve lumbar pain and instability (Goldby et al., 2006; Kavcic et al., 2004; Kim and Kim, 2018). Thus, the participants in our study were placed on this training with the aim of restoring the activation pattern of the deep stabilizing muscles of the spine to achieve these desired therapeutic effects.

Promising results were also demonstrated in this study in terms of improved pain intensity and functional disability. The effect sizes were also large, thus suggesting that the magnitude of the changes observed was clinically relevant. This indicates the ability of stabilization exercise as also reported by many authors (Akodu and Akindutire, 2018; Bhadauria and Gurudut, 2017; Ibrahim et al., 2018; Ojoawo et al., 2017) to improve symptoms of pain and disability in patients with CNLBP in the short-term. However, contrary to the findings of previous studies (Golby et al., 2006; Shaughnessy and Caulfield, 2004), we found no significant differences in the physical and mental health outcomes after the intervention which might be partly explained by the shorter treatment sessions (12 treatment sessions) provided. Most studies reporting significant improvement in quality of life in patients with CNLBP have longer treatment sessions ( $\geq 16$ treatment sessions) (Goldby et al., 2006; Macedo et al., 2012; Shaughnessy and Caulfield, 2004).

One obvious limitation of this study is the quasi-experimental design without a control group hence, limiting the study's ability to conclude a causal association between the intervention and outcomes. Another obvious limitation is the small sample size and as such the results should be interpreted with caution. Furthermore, outcomes were assessed in the short-term. However, it is important to note that this is a pilot study conducted to evaluate the feasibility of a future, large powered RCT so that resources and efforts are not wasted. Using the results of the present study, refinement of the larger RCT will be done especially regarding the use of comparative and control groups, inclusion criteria (e.g., broader age range), the number of sessions required to induce changes in quality of life, longer follow-ups and other procedural aspects of the study. The results will also be considered in calculating the sample size needed for the future, large RCT.

In conclusion, this pilot study suggest that it is feasible with 
minor adjustment to conduct a larger scale, powered RCT to examine the efficacy of spinal stabilization exercise with RUSI biofeedback in individuals with CNLBP.

\section{CONFLICT OF INTEREST}

No potential conflict of interest relevant to this article was reported.

\section{ACKNOWLEDGMENTS}

The authors would like to thank all the participants for their participation in the study.

\section{REFERENCES}

Akbari A, Khorashadizadeh S, Abdi G. The effect of motor control exercise versus general exercise on lumbar local stabilizing muscles thickness: randomized controlled trial of patients with chronic low back pain. J Back Musculoskelet Rehabil 2008;21:105-112.

Akodu AK, Akindutire OM. The effect of stabilization exercise on pain-related disability, sleep disturbance, and psychological status of patients with non-specific chronic low back pain. Korean J Pain 2018;31:199-205.

Alaranta H, Tallroth K, Soukka A, Heliövaara M. Fat content of lumbar extensor muscles and low back disability: a radiographic and clinical comparison. J Spinal Disord 1993;6:137-140.

Balagué F, Mannion AF, Pellisé F, Cedraschi C. Non-specific low back pain. Lancet 2012;379:482-491.

Beaton DE, Bombardier C, Guillemin F, Ferraz MB. Guidelines for the process of cross-cultural adaptation of self-report measures. Spine (Phila Pa 1976) 2000;25:3186-3191.

Bhadauria EA, Gurudut P. Comparative effectiveness of lumbar stabilization, dynamic strengthening, and Pilates on chronic low back pain: randomized clinical trial. J Exerc Rehabil 2017;13:477-485.

Chiarotto A, Maxwell LJ, Terwee CB, Wells GA, Tugwell P, Ostelo RW. Roland-Morris Disability Questionnaire and Oswestry Disability Index: which has better measurement properties for measuring physical functioning in nonspecific low back pain? Systematic review and meta-analysis. Phys Ther 2016;96:1620-1637.

Chou R. Low back pain (chronic). BMJ Clin Evid 2010;2010:1116.

Dagenais S, Caro J, Haldeman S. A systematic review of low back pain cost of illness studies in the United States and internationally. Spine J $2008 ; 8: 8-20$

Danneels LA, Vanderstraeten GG, Cambier DC, Witvrouw EE, De Cuyper HJ. CT imaging of trunk muscles in chronic low back pain patients and healthy control subjects. Eur Spine J 2000;9:266-272.

Ehsani F, Hedayati R, Bagheri R, Jaberzadeh S. The effects of stabilization exercise on the thickness of lateral abdominal muscles during standing tasks in women with chronic low back pain: a randomized tripleblinded clinical trial study. J Sport Rehabil 2019 Dec 9 [Epub]. https:// doi.org/10.1123/jsr.2019-0058.

Goldby LJ, Moore AP, Doust J, Trew ME. A randomized controlled trial investigating the efficiency of musculoskeletal physiotherapy on chronic low back disorder. Spine (Phila Pa 1976) 2006;31:1083-1093.

Hartvigsen J, Hancock MJ, Kongsted A, Louw Q, Ferreira ML, Genevay S, Hoy D, Karppinen J, Pransky G, Sieper J, Smeets RJ, Underwood M; Lancet Low Back Pain Series Working Group. What low back pain is and why we need to pay attention. Lancet 2018;391:2356-2367.

Henry SM, Teyhen DS. Ultrasound imaging as a feedback tool in the rehabilitation of trunk muscle dysfunction for people with low back pain. J Orthop Sports Phys Ther 2007;37:627-634.

Henry SM, Westervelt KC. The use of real-time ultrasound feedback in teaching abdominal hollowing exercises to healthy subjects. J Orthop Sports Phys Ther 2005;35:338-345.

Hides J, Gilmore C, Stanton W, Bohlscheid E. Multifidus size and symmetry among chronic LBP and healthy asymptomatic subjects. Man Ther 2008;13:43-49.

Hides JA, Richardson CA, Jull GA. Multifidus muscle recovery is not automatic after resolution of acute, first-episode low back pain. Spine (Phila Pa 1976) 1996;21:2763-2769.

Hides JA, Stanton WR, McMahon S, Sims K, Richardson CA. Effect of stabilization training on multifidus muscle cross-sectional area among young elite cricketers with low back pain. J Orthop Sports Phys Ther 2008;38:101-108.

Hides JA, Stanton WR, Mendis MD, Gildea J, Sexton MJ. Effect of motor control training on muscle size and football games missed from injury. Med Sci Sports Exerc 2012;44:1141-1149.

Hildebrandt M, Fankhauser G, Meichtry A, Luomajoki H. Correlation between lumbar dysfunction and fat infiltration in lumbar multifidus muscles in patients with low back pain. BMC Musculoskelet Disord 2017;18:12.

Hoy D, Bain C, Williams G, March L, Brooks P, Blyth F, Woolf A, Vos T, Buchbinder R. A systematic review of the global prevalence of low back pain. Arthritis Rheum 2012;64:2028-2037.

Ibrahim AA, Akindele MO, Bello B, Kaka B. Translation, cross-cultural adaptation, and psychometric properties of the Hausa versions of the numerical pain rating scale and global rating of change scale in a low-literate population with chronic low back pain. Spine (Phila Pa 1976) 2020a;45:E439-E447.

Ibrahim AA, Akindele MO, Ganiyu SO. Motor control exercise and pa- 
tient education program for low resource rural community dwelling adults with chronic low back pain: a pilot randomized clinical trial. J Exerc Rehabil 2018;14:851-863.

Ibrahim AA, Akindele MO, Ganiyu SO, Kaka B, Abdullahi BB, Sulaiman SK, Fatoye F. The Hausa 12-item short-form health survey (SF-12): Translation, cross-cultural adaptation and validation in mixed urban and rural Nigerian populations with chronic low back pain. PLoS One 2020b;15:e0232223.

Kader DF, Wardlaw D, Smith FW. Correlation between the MRI changes in the lumbar multifidus muscles and leg pain. Clin Radiol 2000;55: 145-149.

Kamaz M, Kireşi D, Oğuz H, Emlik D, Levendoğlu F. CT measurement of trunk muscle areas in patients with chronic low back pain. Diagn Interv Radiol 2007;13:144-148.

Kavcic N, Grenier S, McGill SM. Quantifying tissue loads and spine stability while performing commonly prescribed low back stabilization exercises. Spine (Phila Pa 1976) 2004;29:2319-2329.

Kim DH, Kim TH. Comparison of the effects of stability exercise and balance exercise on muscle activity in female patients with chronic low back pain. J Exerc Rehabil 2018;14:1053-1058.

Kovacs FM, Garcia E, Royuela A, González L, Abraira V; Spanish Back Pain Research Network. Prevalence and factors associated with low back pain and pelvic girdle pain during pregnancy: a multicenter study conducted in the Spanish National Health Service. Spine (Phila Pa 1976) 2012;37:1516-1533.

Lee DH, Hong SK, Lee YS, Kim CH, Hwang JM, Lee Z, Kim JM, Park D. Is abdominal hollowing exercise using real-time ultrasound imaging feedback helpful for selective strengthening of the transversus abdominis muscle? A prospective, randomized, parallel-group, comparative study. Medicine (Baltimore) 2018;97:e11369.

Louw QA, Morris LD, Grimmer-Somers K. The prevalence of low back pain in Africa: a systematic review. BMC Musculoskelet Disord 2007; 8:105.

Luo X, Pietrobon R, Sun SX, Liu GG, Hey L. Estimates and patterns of direct health care expenditures among individuals with back pain in the United States. Spine (Phila Pa 1976) 2004;29:79-86.

Macedo LG, Latimer J, Maher CG, Hodges PW, McAuley JH, Nicholas MK, Tonkin L, Stanton CJ, Stanton TR, Stafford R. Effect of motor control exercises versus graded activity in patients with chronic nonspecific low back pain: a randomized controlled trial. Phys Ther 2012;92: 363-377.
Maraschin M, Ferrari S, Cacciatori C. The effect of functional stabilization training on the cross sectional area of the deep stabilizers muscles in healthcare workers with chronic low back pain: a pilot study. Sci Riabil 2014;16:e21.

Mengiardi B, Schmid MR, Boos N, et al. Fat content of lumbar paraspinal muscles in patients with chronic low back pain and in asymptomatic volunteers: quantification with MR spectroscopy. Radiology 2006;240: 786-792.

Morris LD, Daniels KJ, Ganguli B, Louw QA. An update on the prevalence of low back pain in Africa: a systematic review and meta-analyses. BMC Musculoskelet Disord 2018;19:196.

Ojoawo AO, Hassan MA, Olaogun MOB, Johnson EO, Mbada CE. Comparative effectiveness of two stabilization exercise positions on pain and functional disability of patients with low back pain. J Exerc Rehabil 2017;13:363-371.

Omokhodion FO. Low back pain in a rural community in South West Nigeria. West Afr J Med 2002;21:87-90.

Roland M, Fairbank J. The Roland-Morris Disability Questionnaire and the Oswestry Disability Questionnaire. Spine (Phila Pa 1976) 2000;25: 3115-3124.

Shamsi M, Sarrafzadeh J, Jamshidi A, Zarabi V, Pourahmadi MR. The effect of core stability and general exercise on abdominal muscle thickness in non-specific chronic low back pain using ultrasound imaging. Physiother Theory Pract 2016;32:277-283.

Shaughnessy M, Caulfield B. A pilot study to investigate the effect of lumbar stabilisation exercise training on functional ability and quality of life in patients with chronic low back pain. Int J Rehabil Res 2004;27: 297-301.

Sokunbi O, Watt P, Moore A. A randomised controlled trial (RCT) on the effects of frequency of application of spinal stabilisation exercises on multifidus cross sectional area (MFCSA) in participants with chronic low back pain. Physiother Singapore 2008;11:9-16.

Tella BA, Akinbo SR, Asafa SA, Gbiri CA. Prevalence and impacts of low back pain among peasant farmers in south-west Nigeria. Int J Occup Med Environ Health 2013;26:621-627.

Thabane L, Ma J, Chu R, Cheng J, Ismaila A, Rios LP, Robson R, Thabane M, Giangregorio L, Goldsmith $\mathrm{CH}$. A tutorial on pilot studies: the what, why and how. BMC Med Res Methodol 2010;10:1.

Van K, Hides JA, Richardson CA. The use of real-time ultrasound imaging for biofeedback of lumbar multifidus muscle contraction in healthy subjects. J Orthop Sports Phys Ther 2006;36:920-925. 